natraemia develops with great rapidity, and seizures and coma can quickly supervene. ${ }^{3}$

In a review of 'abuse dwarfism'4 it was noted that the characteristic features of psychosocial deprivation might include, among others, "A history of unusual eating and drinking behaviour, reversible on change of domicile, such as eating from a garbage can and drinking from a lavatory, polydipsia and polyphagia, enuresis and encopresis, and pathological family relationships, including unusual cruelty and neglect, either somatic or psychic, or both'.

Although this child was not dwarfed the events reported include many of the behavioural signs Money listed. ${ }^{4}$ However, it remains unclear whether the acute water intoxication was the result of voluntary excessive drinking as a manifestation of deprivation or starvation or, as the child stated, was because of forced water ingestion from the hose inserted in his mouth. The latter seems a more probable, albeit bizarre, explanation. Presumably if water is forcibly introduced into the oral cavity by hose the victim has only two options. Either he inhales the water with the probability of drowning or he swallows the water with the consequence of acute water intoxication. We suggest that forced water intoxication be added to the growing list of rare manifestations of child abuse.

\section{References}

1 Kempe C H. Uncommon manifestations of the battered child syndrome. Am J Dis Child 1975; 129 : 1265.

2 Dugan S, Holliday M A. Water intoxication after voluntary fluid ingestion. Pediatr 1967; 39: 418-20.

3 Kohn B, Norman M E, Feldman H, Thier S O, Singer I. Hysterical polydipsia (compulsive water drinking) in children. Am J Dis Child 1976; 130: 210-2.

4 Money J. The syndrome of abuse dwarfism (psychosocial dwarfism or reversible hyposomatotropism). Am J Dis Child 1977; 131 : 508-513.

Correspondence to Professor J G Mortimer, Department of Paediatrics and Child Health, University of Otago Medical School, PO Box 913, Dunedin, New Zealand.

\title{
Hypoxia in a neonate caused by intermittent positive pressure ventilation
}

\section{R BEDDIS AND M SILVERMAN}

\section{Department of Paediatrics and Neonatal Medicine, Hammersmith Hospital, London}

SUMMARY A newborn baby receiving mechanical ventilation was noted to have an extremely variable degree of hypoxia, despite the administration of $100 \%$ oxygen. The hypoxia was relieved rapidly when mechanical ventilation was withdrawn.

Although intermittent positive pressure ventilation (IPPV) may improve arterial oxygenation it may also cause a number of adverse haemodynamic effects, notably an increase in pulmonary vascular resistance and a decrease in cardiac output. ${ }^{1}$ In the neonate an increase in pulmonary vascular resistance may result in extrapulmonary right-to-left shunts through the foramen ovale and ductus arteriosus.

We report a case in which hypoxia occurred during unnecessary IPPV of a neonate. The hypoxia improved and the fractional inspired oxygen $\left(\mathrm{F}_{1} \mathrm{O}_{2}\right)$ concentration was greatly reduced when IPPV was stopped.

\section{Case report}

A boy weighing $1290 \mathrm{~g}$ was born at another hospital by assisted breech delivery with forceps applied to the aftercoming head, after spontaneous onset of labour at 29 weeks' gestation. The Apgar score at one minute was 5 ; only pharyngeal suction and oxygen administration via face mask were required. Grunting and subsostal recession were noted from birth and although he was nursed in $50 \%$ oxygen, neither blood-gas measurements nor a chest $x$-ray was done at this stage. At $\mathbf{3 0}$ minutes the baby's colour was poor and IPPV was started by oro-tracheal tube, with $100 \%$ oxygen at pressures of $20 / 0 \mathrm{cmH}_{2} \mathrm{O}$ (peak airways pressure/end expiratory pressure). His condition improved and from $1 \frac{1}{2}$ hours he was ventilated using intermittent mandatory ventilation at 7 breaths $/ \mathrm{min}$.

On transfer to Hammersmith Hospital at 3 hours ventilation was continued at $15 / 0 \mathrm{cmH}_{2} \mathrm{O}, 30$ breaths/min, and 1:1 inspiratory:expiratory (I:E) ratio. These settings were maintained until $10 \mathrm{~min}$ before mechanical ventilation was stopped. Arterial oxygen tension $\left(\mathrm{PaO}_{2}\right)$ was monitored by an umbilical arterial catheter-tip oxygen electrode (Searle) and it was noted that there were wide fluctuations in $\mathrm{PaO}_{2}$. This was confirmed by monitoring transcutaneous oxygen tension $\left(\mathrm{TcPo}_{2}\right)$ (Radiometer): recordings were made on a chart recorder (Devices). 
During this period, wide fluctuations in $\mathrm{PaO}_{2}$ occurred (Fig. 1, left), the extent of which exceeded the capacity of the pen recorder. On other occasions there were briefly sustained episodes of hypoxia (Fig. 1, centre). Formal blood-gas analysis confirmed the $\mathrm{PaO}_{2}$ changes, while arterial $\mathrm{pH}$ varied between $7 \cdot 13$ and $7 \cdot 29$ during this period. Arterial carbondioxide tension $\left(\mathrm{PaCO}_{2}\right)$ remained low throughout the period of IPPV, the highest recorded value being $3.7 \mathrm{kPa}(28 \mathrm{mmHg})$. Systolic blood pressure on arrival was $55 \mathrm{mmHg}$. Using the continuous $\mathrm{PaO}_{2}$ reading from the umbilical arterial electrode, an attempt was made to manage the baby's oxygen requirements by servo-control, ${ }^{2}$ but the wide fluctuations made adequate control impossible.

A chest $x$-ray was normal and at 14 hours it was decided to stop IPPV. The oxygen requirements and $\mathrm{TcPo}_{2}$ during the period of withdrawal are shown in Fig. 2. $\left(\mathrm{TcPO}_{2}\right.$ is shown due to a failure of the $\mathrm{PaO}_{2}$

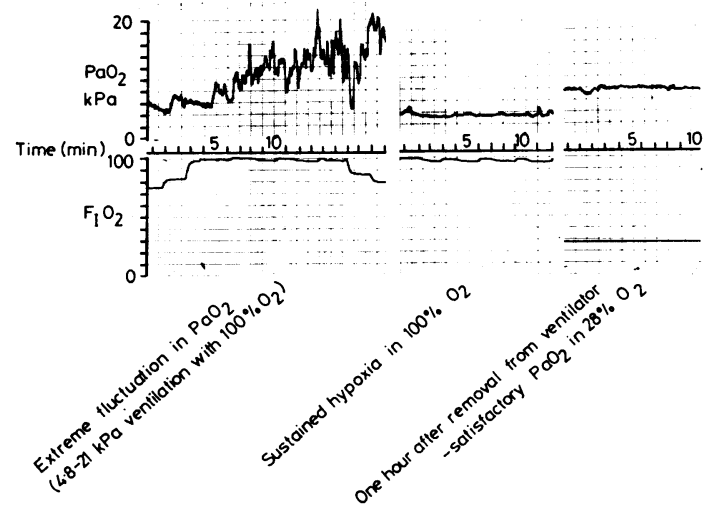

Fig. 1 Variation in oxygen requirements and arterial oxygen tension.

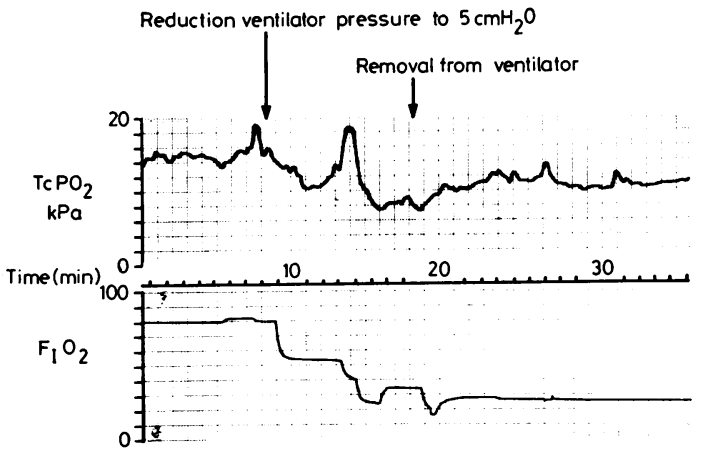

Fig. 2 Reduction in oxygen requirements after removal from ventilator. recording at that time.) At that stage, the first step was a reduction in the peak pressure to $5 \mathrm{cmH}_{2} \mathrm{O}$, while the other ventilator settings were unchanged. This produced a sudden fall in oxygen requirement. When mechanical ventilation was stopped, the baby maintained a steady, satisfactory $\mathrm{PaO}_{2}$ in $28-30 \%$ oxygen. The $\mathrm{PaO}_{2}$ and $\mathrm{F}_{1} \mathrm{O}_{2}$ one hour later are shown (Fig. 1, right). Within 24 hours the condition of the baby was satisfactory in air and no subsequent problems were encountered.

\section{Discussion}

Studies in animals have shown that an increase in pulmonary vascular resistance and a decrease in cardiac output occur during IPPV, and associated with this, there is an increase in right atrial pressure. ${ }^{1}$ These effects are exacerbated by increasing the inspiratory pressure and the inspiratory:expiratory ratio. ${ }^{3}$ The increase in pulmonary vascular resistance may be due to pulmonary vascular distortion with increasing lung volume, to the direct effect on pulmonary capillary flow of a rise in alveolar pressure, ${ }^{4}$ and possibly, to the effect of increased intrathoracic pressure on left heart function. ${ }^{5-6}$ In the neonate, an increase in right atrial pressure will result in shunting of blood through the foramen ovale and, if pulmonary artery pressure exceeds systemic pressure, across the ductus arteriosus. The haemodynamic disturbances due to IPPV may be expected to be less in babies with stiff lungs, since both the pressure transmitted to the mediastinal structures ${ }^{7}$ and the effect on lung volume will be less than in normal babies.

The rapid swings in $\mathrm{PaO}_{2}$ that occurred in this case must have been due to variable right-to-left shunting during lung inflation, exacerbated by spontaneous respiratory efforts. The episodes of more persistent hypoxia were due to continuous right-to-left shunting. Estimation of the right-to-left shunt showed that it varied from 30 to $60 \%$ during short periods of time. With the normal chest $x$-ray and subsequently normal $\mathrm{PaO}_{2}$ in $28 \%$ oxygen, it is unlikely that ventilation/perfusion imbalance played more than a small part in the hypoxia, which must therefore have been due to an extrapulmonary shunt.

Nelson et al. ${ }^{8}$ described a similar effect with continuous positive airways pressure (CPAP) in a small proportion of the cases they studied. Hypoxia was relieved by decreasing or stopping CPAP.

Faced with a hypoxic baby being ventilated with $100 \%$ oxygen and with a normal chest $x$-ray, the main diagnoses to be considered are congenital heart disease and persistent fetal circulation. Consideration of the former may lead to cardiac catheterisation and 
of the latter to the administration of experimental drugs designed to lower pulmonary vascular resistance. There may also be a temptation to increase the peak inspiratory pressures in such a situation. In the case described, any of the above measures might have had dire consequences.

We have seen hypoxia relieved by stopping IPPV on previous occasions, but have been unable to document the event. We have also seen patients with bronchopulmonary dysplasia whose early neonatal course was similar to that described above.

The indications for IPPV were obscure and this case serves as a reminder that IPPV should not be undertaken without good reason. It also emphasises the importance of proper assessment of a patient after transfer from another hospital.

\section{References}

1 Andersen M N, Kuchiba K. Depression of cardiac output with mechanical ventilation. $J$ Thorac Cardiovasc Surg 1967; 54: 182-90.

2 Beddis I R, Collins P, Levy N M, Godfrey S, Silverman M.
A new technique for the servo-control of arterial oxygen tension in preterm infants. Arch Dis Child 1979; 54: 278-80.

3 Morgan B C, Martin W E, Hornbein T F, Crawford E W, Guntheroth W G. Hemodynamic effects of intermittent positive pressure respiration. Anesthesiology 1966; 27: 585-90.

4 West J B. Ventilation/blood flow and gas exchange. 3rd ed. Oxford: Blackwell Scientific, 1977: 15-32.

5 Lamy M L, Fallat R J, Eberhart R C, et al. Decreased left ventricular output with PEEP in normal men and dogs in closed and open chest conditions (abstract). Am Rev Respir Dis 1979; 119: No. 4, part 2, 377.

- Wise $\mathbf{R}$ A, Robotham J L, Bromberger-Barnea B, Permutt S. Mechanism of elevation of left atrial pressure due to PEEP (abstract). Am Rev Respir Dis 1979; 119: No. 4, part 2, 392.

7 Milner A D, Saunders R A, Hopkin I E. Effect of continuous distending pressure on lung volume and lung mechanics in the immediate neonatal period. Biol Neonate 1977; 31 : 111-5.

8 Nelson R M, Egan E A, Eitzman D V. Increased hypoxemia in neonates secondary to the use of continuous positive airway pressure. J Pediatr 1977; 91 : 87-91.

Correspondence to $\mathrm{Dr} M$ Silverman, Department of Paediatrics and Neonatal Medicine, Hammersmith Hospital, Du Cane Road, London W12 OHS.

\title{
Eucalyptus oil poisoning
}

\author{
S PATEL AND J WIGGINS
}

Department of Paediatrics, East Birmingham Hospital, Birmingham

SUMMARY Accidental ingestion of eucalyptus oil by a 3-year-old boy caused profound central nervous system depression within $\mathbf{3 0}$ minutes, but he recovered rapidly after gastric lavage. The extreme toxicity of eucalyptus oil is emphasised.

Eucalyptus oil is a traditional remedy for a variety of common ailments, particularly of the respiratory tract. It is cheap, freely available, and found in many households. However, its extreme toxicity is not generally appreciated and reports of poisonings are rare. With this in mind we report a recent ingestion of eucalyptus oil that was nearly fatal.

\section{Case report}

A 3-year-old Muslim boy was seen within 30 minutes of ingesting about $10 \mathrm{ml}$ eucalyptus oil. On examination he was deeply comatose and his breath smelt strongly of eucalyptus. The pupils were constricted, muscle tone was markedly reduced, and his tendon reflexes could not be elicited. His respirations were shallow and irregular at a rate of $10 / \mathrm{min}$. The pulse rate was 70 beats $/ \mathrm{min}$ and the blood pressure $75 / 40 \mathrm{mmHg}$. Biochemical investigations on admission included a serum urea of $6.3 \mathrm{mmol} / 1$ $(38 \mathrm{mg} / 100 \mathrm{ml})$, with normal electrolytes. Initial treatment included the insertion of a cuffed endotracheal tube (which produced no gag reflex), and gastric lavage with sodium bicarbonate solution. Sodium sulphate $100 \mathrm{ml}$ was left in the stomach as a cathartic.

By 2 hours after admission his pulse, blood pressure, and respiration rate had gradually returned to normal. After 5 hours consciousness had gradually been regained, and by 24 hours physical examination was normal apart from a faint smell of eucalyptus on the breath. Urinary output remained satisfactory throughout. He was discharged home 48 hours after admission. 